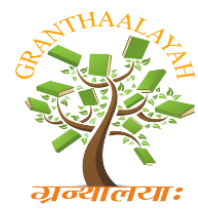

INTERNATIONAL JOURNAL OF RESEARCH GRANTHAALAYAH

A knowledge Repository

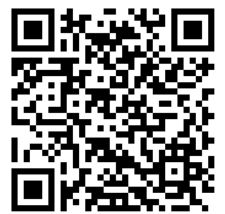

Social

\title{
RESEARCH WRITING: FROM ELUSIVE PEDAGOGY TO EXCLUSIVE PEDAGOGY
}

\author{
Mr. Rajashekar Gummaraju ${ }^{* 1}$ \\ ${ }^{* 1}$ Assistant Professor, Department of English, University College of Arts, Tumkur University, \\ Tumkur-572 103, Karnataka, INDIA
}

\begin{abstract}
Recent years have seen an increased attention being given to thesis and dissertation writing in the ESP literature. Prior (1995) attributes more to a thesis or a dissertation than its rhetorical structure. He lists the factors which influence decisions students make about the form of their text-the research perspective taken up in the study, the purpose of the text, and the extent to which the students have been given advice on the positioning and organisation of their text, etc. For Paltridge (2002), thesis and dissertation writing is a difficult process for native speaker students and often doubly so for non-native speaker students. ESL students may have the level of language proficiency required for admission to their course of study, but not yet the necessary textual knowledge, genre knowledge and social knowledge (Bhatia, 1999) required of them to succeed in this particular setting. Our students need to be presented with the range of thesis options that might be open to them, and consider the reasons why they might make a particular choice. There is no such a thing as "one size fits all" master's and doctoral thesis. The present paper attempts to look at the pedagogies evolved for teaching research writing.
\end{abstract}

Keywords:

creating research space, rhetoricity, macrogenre, knowledge-telling, knowledge-transforming, disciplinary research community, heuristic undertaking.

Cite This Article: Mr. Rajashekar Gummaraju, "RESEARCH WRITING: FROM ELUSIVE PEDAGOGY TO EXCLUSIVE PEDAGOGY" International Journal of Research Granthaalayah, Vol. 4, No. 4 (2016): 115-123.

\section{INTRODUCTION}

With the emergence of English as a powerful language of publication in the international knowledge-manufacturing industry, teaching of research paper has worked out some space for itself, with more than half the number of publications across the globe being in English, it can be said that English has remained the language of research and will do so for many more years. This is also the reason why the contribution of NNS researchers in Anglo-centric research is marginal. ESL scholars and EAP instructors have the greater responsibility of preparing NNS researchers 
and assisting them in their research. Suresh Canagarajah (2002) presents the same concern about the marginalisation of NNS scholars in knowledge production processes. The widely recognised and acknowledged difficulty of research writing is also a cause for worry and taking research English more seriously.

\section{ABSENCE OF CONTINUUM IN CURRICULUM FOR WRITING RESEARCH}

When ESL scholars are experiencing difficulties in research writing, NNS researchers are sure to find the exercise of research writing mazy and unattainable. In John Swales' (1987) view, teaching research paper to Non-native Speaker (NNS) graduate students is not enjoyed by ESL instructors. Many teachers feel that such teaching requires competence which is beyond their domain. Lack of required level of expertise and exposure to EAP by many teachers and instructors is another reason why teaching research paper has retained Cinderella status.

Writing, particularly writing the thesis, is a challenge for most students. Students and supervisors, in many online surveys, ranked writing the thesis as both the most important and the most challenging writing task of doctoral candidature. Several supervisors feel that they do not have either the time or the required expertise to teach the language of doctoral writing. Bruce (2008) calls the focus on strengthening of the professional development of $\mathrm{PhD}$ supervision only tangential and recent and this has left the research students unclear in terms of what to expect from doctoral writing. He also stresses the need to identify appropriate pedagogies to develop students' academic writing skills, as well as the need for further dialogue on how best to deliver support.

Mauch \& Birch (1988) in Brian Paltridge (2002) frown on the literature on thesis and dissertation writing saying it consists of handbooks and guides with, apart from a few notable exceptions, very little analysis having been carried out of actual texts. Dudley-Evans (1993) and Thompson (1999) point to the variations in expectations across disciplines, fields of study, in terms of what a thesis or dissertation should look like. For example, a thesis or dissertation written in some areas of study is now very different from one that might have been written 10 or more years ago, particularly with the influence of what Hodge (1998, p. 113) terms the 'postmodern turn' in the 'new humanities' and social sciences. Dudley-Evans (1995, 1999) claims that in spite of similarity between theses and dissertations on the one hand and other pieces of research writing, such as research articles, on the other, they are different in many ways.

Rosemary S Caffarella \& Bruce G Barnett (2000) voice the concern shared by many already regarding the absence of research in undergraduate curriculum that lands the supervisors and postgraduate teachers in a pool of stress when they realise that their research students are novice as much to the act of research as to the process of writing. It shocks them that their students not only do not write like scholars but they also do not think like scholars. In general, many faculty observe that teaching the scholarly writing process often comes in the form of 'too little too late'. In particular, some students may not be exposed to the scholarly writing process until the dissertation, which may have significant implications for the completion of their doctoral programme. The pertinent question that faculty think appropriate to address themselves at this 
stage is -Is there a better way to teach novice scholars what we know about the seemingly mysterious process of scholarly writing?

Little attention has been given in the literature to graduate students' perceptions of scholarly writing process or to what they have found useful in programmes designed to teach academic writing. There are only a handful of empirical studies which sought students' opinions to the writing process (Torrance et al, 1992, 1993, 1994; Koncel \& Carney, 1992; Bishop, 1993; Torrance \& Thomas, 1994), particularly the perceptions of students regarding writing in graduate-level programmes. For instance, Koncel \& Carney (1992, in Caffarella \& Barnett, 2000) found a discrepancy between graduate students in social work programmes and faculty as to what constituted effective scholarly writing, discovering that students wanted to learn how to write more concisely, follow a prescribed format and use correct terminology. Faculty, on the other hand, felt that students needed to improve their ability to make solid arguments supported by empirical evidence and theory.

Torrance and colleagues found that graduate students' notions were quite different from those of novice undergraduate writers, and approximately similar to those of productive academics. However, a significant minority of research students reported writing difficulties that might hinder their successful completion of research degrees (Torrance et al, 1992, pp. 155). They also identified three distinct strategies students used in approaching their written work; planning, revising and mixed strategies. Although these authors acknowledged that planning was important in the writing process, it was 'neither a necessary nor a sufficient condition for writing success' (Torrance et al, 1994, pp. 379). Instead, both 'think-then-write 'and think-while-you-write' strategies have utility in the context of academic writing' (Torrance et al, 1994, pp. 390).

\section{RESEARCH WRITING: ELUSIVE PEDAGOGY?}

Torrance et al (1992) argue out a case for some form of writing training to be provided to graduate students, but warns that 'it is not at all clear what form this writing instruction should take' (pp. 165). They conclude that graduate students benefit from short-term writing courses; however, no one form of writing instruction is suitable for all students. Rather, they advise that different instructional approaches should be incorporated and that students should be allowed to choose those which fitted their needs. Regardless, 'whatever form the instruction takes, it should focus on the production of text, and not solely on the sorting out of ideas prior to putting on to paper (Torrance \& Thomas, 1994, pp. 120). The authors designed a process, the Scholarly Writing Project (SWP), for teaching doctoral students academic writing, which incorporated the writing and rewriting of text as a key component of the activity.

The SWP had three major purposes: 1) to investigate a specific area of interest focusing on the content of the class; 2) to engage in the process of critiquing a colleague's work; and 3) to incorporate feedback from colleagues and instructors in preparing a formal academic paper.

The product scholarly writing differed greatly between graduate and undergraduate students as well as between novice and experienced academic scholars (Hartley \& Branthwaite, 1989; Torrance et al, 1992). 
Torrance et al find that the current literature on critiquing, and especially on receiving critiques, almost totally ignores the positive and negative emotional aspects of receiving feedback on one's writing. Rather, the typical advice given is to be non-defensive when receiving feedback and to learn how to manage negative feedback with grace (Rudestam \& Newton, 1992). Lamott (1994, in Caffarella \& Barnett, 2000) does the best job in exploring the emotionality of receiving feedback on one's work. Lamott also observes that whereas writing alone can be less painful, receiving feedback from others helps improve her work. When teaching novice scholars about the scholarly writing process, it is important to acknowledge their emotions, both good and bad, as legitimate and healthy reactions since they are developing the skills needed to become successful writers.

Treatment of the scholarly writing process, for Torrance et al, should include more in-depth material about both giving and receiving feedback. This might include guidelines as to what skills reviewers should possess, what types of feedback to include in the critiquing process, how to handle conflicting feedback from different professors, and an acknowledgement that being critiqued is both a rational and an emotional process for most people, especially for novice scholars.

Research article is a product that varies from one field to another in terms of its conventionality and standardization. Miller (1984, pp. 165) in Swales (1987) argues that "what we learn when we learn a genre is not just a pattern of forms or even a method of achieving our own ends. We learn, more importantly, what ends we have". By exposing the students to the research genres available, we make them aware of the endless possibilities they have before them and they can also visualise the framework of their own research.

\section{RESEARCH WRITING: A GENRE BY ITSELF}

While Widdowson (1983a) in Swales (1987) calls research paper a 'macrogenre', for Swales it is essential to study research paper in the background of a) Sociology of Science b) Citation Analysis c) Technical Writing and d) EAP. He also finds history of research writing and research into higher education necessary for a holistic study of research paper. Research paper is much more than a mere recording of facts or figures; it has its own quite separate conventions, its own processes of literary reasoning, and its own standards of argument. The model of research suggested by Swales (1986) uses the ecological metaphor of 'creating a research space' (CARS, for short).

Bloch quoted in Stephanie A. Schlitz (2010) takes the position that "in order to become successful academic writers, college student writers must understand how (their) grammatical choices...can affect their credibility as researchers and enhance the rhetorical impact of (a) claim".

Schlitz observes that corpus-informed approaches to writing research have held the forum since the latter half of the twentieth century. Teachers and researchers from various fields including EAP are using corpus-based approaches to enhance their L2 writing pedagogy in areas like genre knowledge (e.g. Henry \& Roseberry, 2001), grammatical knowledge (e.g. Diniz \& Moran, 2005, Cleas, 2000) and Citation Practices (e.g. Thompson and Tribble, 2001). 
The developers of the British Academic Written English (BAWE) hold that the corpus has the potential to chart growth patterns such as whether students' arguments became more complex as their education advanced, whether they learned to integrate material from different sources in formulation conclusions (Nesi et al. 2004. pp. 446).

Sue Ann Johnson (1985) suggests integration of research and composition skills as it has yielded good results in North American universities by providing adequate rehearsal for $\mathrm{PhD}$ thesis writing. There aren't many books available for second language learners in teaching research writing, particularly in developing countries.

Lee (1998) quoted in Sara Booth (2007) refutes the nineteenth century notion of the author as the 'writer-writes-alone' and says it has now been replaced with co-productive and collaborative partnerships which shift the focus from a sole author to a discursive community. Lee also feels that little attention has been given to making writing central to the work of knowledge production in research; rather it is treated as marginal and ancillary. While Threadgold (1993, in Sara Booth, 2007) believes that research texts and textual practices surrounding research construct writing as rational and objective, Lee (1997, in Sara Booth, 2007) and Lee \& Boud (2003, in Sara Booth, 2007) seem to consider research writing as a personal production of knowledge.

\section{CREATING SPACE FOR TEACHING RESEARCH WRITING}

Bruce (2008) is of the opinion that introductory writing workshops contribute mainly to the first stage of development in student writing, that of being able to deconstruct and reconstruct the discourses of the discipline. It follows that further concurrent programmes such as coursework writing subjects and/or writing circles and writing retreats are necessary to move this foundation work through the stages of developing authorial voice and identity and achieving critical competence. Clear, systematic and institutionalised development of student writing should be a high priority for undergraduate and postgraduate coursework programmes to create better transition experiences. Particular attention should be paid to the explicit transitions that occur in the development of scientific writing skills from undergraduate to honours, honours to research, Masters or $\mathrm{PhD}$ programmes and from the early to later stages of $\mathrm{PhD}$ candidature. Janice Catterall et al attribute the underdevelopment of doctoral writing skills among research students to the lack of recognition among research students, supervisors and other persons to compartmentalise research writing as a separate skill that needs to be explicitly addressed.

Moragh Paxton (2011) expresses apprehensions about the initiation of students into research at the postgraduate level or honours level directly and underlines the importance of developing research abilities at the undergraduate level. He strongly advocates their enculturation into research process before they enter the main research stream. He also demands sufficient space for the teaching of research writing in the honours curriculum and says learners can't just be expected to develop a 'feel for the game'. More often than not, supervisors don't spell out the format for a research paper or project because they believe that students should discover the appropriate format for themselves by reading research articles. Another reason for this seems to be that genres are not static but ever changing and there is the danger of freezing a genre by over teaching it or naming it repeatedly. Many supervisors and instructors from various institutions 
feel that institutions don't regard writing as central to the real work of research, in fact, they seem to separate writing from the act of researching. They often refer to the 'writing up' of the research project as if it is something that happens rather briefly at the end of the research project. This aspect of differentiating between writing and writing up of research has been touched upon in almost every literature we have seen so far and this continue to surface in the literatures to come.

According to Antonia Dilamar Araujo (in Bazerman, 2010), by providing students with enough opportunities to develop their writing skills, they can gradually graduate from knowledge-telling students to knowledge-transforming, mature writers. Writing instruction in university contexts should also endow graduate students with the knowledge about how they may represent themselves so as to convey their judgments, opinions and commitments and establish a disciplinary voice in their texts. Through practice in varied tasks, they may gain communicative competence. Such knowledge may help students to develop awareness that reviews as genres are one of the forms in which writers may negotiate meanings, share views with readers, and construct knowledge.

Janice Catterall et al (2011) are of the opinion that higher education institutions and universities are under pressure to place research on priority due to many stimuli-the confluence of changing university missions, the changing student and staff populations resulting from widening participation agendas and internationalisation (David, 2010) and the push to enhance productivity through publication (Aitchison, Kamler \& Lee, 2010).

Winston \& Field, (2003) in Janice Catterall et al (2011) argue that the research thesis being the capstone of the doctoral candidature has not helped the research students' writing much as there is a widespread dissent regarding their writing abilities among the academics around the world. Aitchison, Kamler \& Lee (2010) in Janice Catterall et al (2011) express their doubts regarding the active publishing abilities of research students. Similarly, Kamler and Thompson (2008) take a dig at the abilities of supervisors to teach writing and say that their students are not well served by formulaic 'advice'. Pare, Starke-Meyerring and McAlpine (2009, pp. 180) go further and state that the "linguistic' and rhetorical complexities of the dissertation are simply inexpressible for most of the academics". With the growing managerial concern to improve both doctoral completion rates and publication rates (Lee \& Kamler, 2007; McGrail, Rickard \& Jones, 2006), it is imperative that institutions address issues of writing pedagogy.

\section{WRITING IN RESEARCH}

Janice Catterall et al place the practice of writing at the centre stage of research and advocate the need for specific understanding of how words operate in the context of research genres like dissertations, proposals, etc. and how writers defend their critical positions as this purpose is not well served by our general understanding of simply knowing how to write. Thus, it is mandatory for the members of the disciplinary research community to possess the required set of skills to be able to represent research. Raimes (1983) in Swales (1987) promotes the idea that writing is a recursive process; writing is heuristic undertaking; and writing is very difficult without the vocabulary to write with. Bruce (2008, pp. 1) in Janice Catterall et al identifies three stages of 
development through which the student writer can successfully launch an academic or professional career.

- Developing knowledge frameworks to be able to deconstruct and reconstruct the discourses of the discipline.

- Developing an 'authorial voice' and an 'identity' within their target discourse community; and

- Developing a critical competence to innovate, challenge, resist and reshape the discourses of their own academic community.

Ken Hyland (2007) hints at the absence of information regarding identification and analysis of text features in courses preparing teachers for second language writing instruction, and teacher education programmes especially in the U.S. Instead, the focus is misdirected towards composition theory, cognitive psychology, or traditional grammars (e.g. Matsuda, 2003). Increasingly, however, we have grown even more conscious that these dominant pedagogical orthodoxies are unable to address language, as well as the writing needs of our students (Christie, 1990; Cope \& Kalantzis, 1993).

Jennifer Nutefall and Phyllis Mentzell Ryder (2005) envisage a broader base for research and say that like writing research is epistemic; we do not merely collect information to confirm a preheld belief; we gather information to complicate a pre-held belief, to test it out, to learn new methods of thinking about it. Research, like writing, is not simply a matter of accomplishing a task, but is a process that can restructure the writer/research's larger worldview and knowledge base.

Composition scholars such as Patricia Bizzell, Kenneth Bruffee and David Bartholomae emphasize that to enter into a discourse community-to learn to write and speak as a participant there-one learns the conventions inscribed in that discourse, the commonplaces, the texts, the gestures and jargon, the interpretive schemes of a group (Bartholomae, 1983). To enter the discourse community of academic writers, one needs to learn the research conventions of scholars and to recognize how research conventions differ across the university. What counts as 'good evidence' in one field is not appropriate in another; one looks for materials for different disciplines in different places and with different methods. Therefore, courses designed to introduce students to the discourse communities surrounding particular topics prepare them to see the rhetoricity in writing and research. Good writing and good research happen when students consider the writing/research process within a particular context, with a particular purpose and with a particular audience. Writing and research must be flexible and shifting to meet the demands of the larger process.

Lucia Thesen (2014) underlines the centrality of the written product-thesis or journal article in the communication of research since the birth of the early modern university in the $18^{\text {th }}$ century. She says, "As fleeting ideas and false starts slowly evolve into settled forms that give material expression to the outcomes of research processes, writing requires us to commit to this path, for now, and leave other paths behind". She talks about the pressure on the novice researchers to produce work that will pass through and travel safely on beyond academic gatekeepers and also a sense of loss experienced by them at the compromises made when developing a written account of their research. In the process of writing, various experiences and modes of expression are 
revised or erased along the way. She politicises this issue of erasures and silences in the contemporary higher education landscape, which is characterised by an unprecedented movement of people, texts and capital.

The pull of the centre means that greater numbers of new researchers are writing in English which is frequently neither their 'home' language nor their primary language of learning (Lillis \& Curry, 2010 in Lucia Thesen, 2014). Swales (2004) and Hyland (2006) offer descriptions of the prevailing research genres in historical and disciplinary context. Other scholars are more concerned with developing pedagogies for teaching research writing. Kamler and Thompson (2006) point out that the writing of research is related to the complex process of developing a research identity. Lillis \& Curry (2010) analyse how the dominance of English is shaping academic publishing.

\section{CONCLUSION}

The pedagogical practices of research writing deserve and demand a separate niche for themselves not just because of the widespread awareness of the importance of the genre but also because of its uniqueness. The observations common to most of the practitioners here areresearch writing requires explicit pedagogical interventions to be addressed and it cannot be taken care of using the usual composition skills exercises. The need for incorporating research studies at the undergraduate level as part of the curriculum is imperative since research students cannot pick up the nuances of research directly at the postgraduate or doctoral level. John Swales (1987) wraps it up properly when he says English has remained the language of research and will do so for many more years. The sanctity and rigour observed in conducting research need good and appropriate representation mechanisms in order to be carried to the world of readers without any loss or dilution in the transit.

\section{REFRENCES}

[1] Antonia Dilamar Araújo, "Academic Genres in University Contexts: An Investigation of Students' Book Reviews Writing as Classroom Assignments”, in International Advances in Writing Research: Cultures, Places, Measures. Ed. Charles Bazerman et al. WAC Clearing House. 2000.

[2] Anthony Paré et al. 2011. "Knowledge and Identity Work in the Supervision of Doctoral Student Writing: Shaping Rhetorical Subjects". Writing in Knowledge Societies. Ed. Doreen Starke-Meyerring et al. WAC Clearing House.

[3] Canagarajah, Suresh A, 2002. "A Geopolitics of Academic Writing”. Orient Longman. New Delhi.

[4] Curry, Mary Jane, and Theresa M. Lillis. 2010. "Academic research networks: Accessing resources for English-medium publishing”. English for Specific Purposes 29.4: 281-295. Print.

[5] Janice Catterall et al. 2011. "Pedagogical Approaches that Facilitate Writing in Postgraduate Research Candidature in Science and Technology". Journal of University Teaching \& Learning Practice. Vol. 8(2).

[6] Jennifer Nutefall, Phyllis Mentzell Ryder. 2005. "Teaching Research Rhetorically". Academic Exchange. pp. 307-311. 
[7] John Swales. 1987. "Utilizing the Literatures in Teaching the Research Paper". TESOL Quarterly. Vol. 21 (1).

[8] Kamler, Barbara, and Pat Thomson. 2006. "Helping Doctoral Students Write: Pedagogies for Supervision”. Education. 154-157.

[9] Ken Hyland. 2007. "Genre Pedagogy: Language, Literacy and L2 Writing Instruction”. Journal of Second Language Writing. Volume 16 pp.148-164

[10] Moragh Paxton. 2011. "How do We Play the Genre Game in Preparing Students at the Advanced Undergraduate Level for Research Writing?" Teaching in Higher Education, 16 (1), pp. 53-64.

[11] Paltridge, Brian. 1997. "Thesis and Dissertation Writing: Preparing ESL Students for Research”. English for Specific Purposes. 16.1. (61-70)

[12] Paltridge, Brian. 2002. "Thesis and Dissertation Writing: An Examination of Published Advice and Actual Practice”: English for Specific Purposes. Vol. 21. pp. 125-143.

[13] "Risk in Academic Writing-Postgraduate Students, Their Teachers and the Making of Knowledge”. Ed. Lucia Thesen and Linda Cooper. Multilingual Matters. U.K. 2014.

[14] Rosemary S Caffarella \& Bruce G. Barnett. 2000. "Teaching Doctoral Students to become Scholarly Writers: The Importance of Giving and Receiving Critiques”. Studies in Higher Education. Vol. 25 (1). pp. 39-52.

[15] Sara Booth. 2007. "Repositioning Research as Writing to Improve Student Learning". Australian Journal of Teacher Education 32 (4). pp. 1-13.

[16] Stephanie A. Schlitz. 2010. "Introduction to the Special Issue: Exploring Corpusinformed Approaches to Writing Research”. Journal of Writing Research. 2(2), pp. 9198.

[17] Sue Ann Johnson. 1985. "An Approach to the Teaching of Academic Writing”. ELT Journal 39 (4). pp. 248-252. 